\title{
Guidelines
}

European Thyroid Journal
Eur Thyroid J 2012;1:216-231

DOI: $\underline{10.1159 / 000346174}$
Received: October 29, 2012

Accepted after revision: November 30, 2012 Published online: December 19, 2012

\section{European Thyroid Association Guidelines for Genetic Testing and Its Clinical Consequences in Medullary Thyroid Cancer}

\author{
R. Elisei ${ }^{a} \quad$ M. Alevizaki ${ }^{\text {b }} \quad$ B. Conte-Devolx ${ }^{c} \quad$ K. Frank-Raue $^{d} \quad$ V. Leite ${ }^{e}$ \\ G.R. Williams ${ }^{f}$

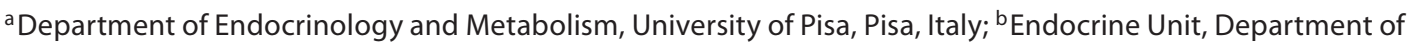 \\ Medical Therapeutics, Athens University School of Medicine, Athens, Greece; 'Department of Endocrinology,

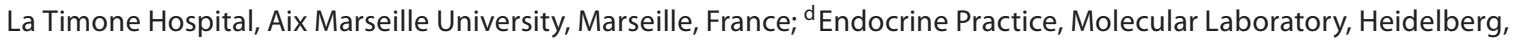 \\ Germany; ${ }^{\text {DDepartment }}$ of Endocrinology, Portuguese Institute of Oncology and CEDOC, Faculty of Medical \\ Sciences, Lisbon, Portugal; ' Molecular Endocrinology Group, Department of Medicine, Hammersmith Hospital, \\ Imperial College London, London, UK
}

\section{Key Words}

Medullary thyroid cancer - Multiple endocrine neoplasia • RET oncogene $\cdot$ Gene carriers $\cdot$ Calcitonin

\begin{abstract}
Twenty-five percent of medullary thyroid cancers (MTC) are familial and inherited as an autosomal dominant trait. Three different phenotypes can be distinguished: multiple endocrine neoplasia (MEN) types $2 \mathrm{~A}$ and $2 \mathrm{~B}$, in which the MTC is associated with other endocrine neoplasias, and familial MTC (FMTC), which occurs in isolation. The discovery that germline RET oncogene activating mutations are associated with $95-98 \%$ of MEN 2/FMTC syndromes and the availability of genotyping to identify mutations in affected patients and their relatives has revolutionized the diagnostic and therapeutic strategies available for the management of these patients. All patients with MTC, both those with a positive familial history and those apparently sporadic, should be submitted to RET genetic screening. Once an RET mutation has been confirmed in an index patient, first-degree relatives should be screened rapidly to identify the $50 \%$ who inherited the mutation and are therefore at risk for development
\end{abstract}

of MTC. Relatives in whom no RET mutation is identified can be reassured and discharged from further follow-up, whereas $R E T$-positive subjects (i.e. gene carriers) must be investigated and a therapeutic strategy initiated. These guideline recommendations are derived from the most recent studies identifying phenotype-genotype correlations following the discovery of causative RET gene mutations in MEN 2 eighteen years ago. Three major points will be discussed: (a) identification of patients and relatives who should have genetic screening for RET mutations, (b) management of asymptomatic gene carriers, and (c) ethics.

Copyright $\odot 2012$ European Thyroid Association Published by S. Karger AG, Basel

\section{Introduction}

Several guidelines have already been published on the diagnosis, management, and treatment of medullary thyroid cancer (MTC) [1-4], but there are no guidelines devoted specifically to RET genetic screening in patients affected by MTC. Because of the rarity of MTC, management should be performed in tertiary referral specialist thyroid cancer centers. Nevertheless, the European Thy-

\begin{tabular}{ll}
\hline KARGER & ( ) 2012 European Thyroid Association \\
Published by S. Karger AG, Basel \\
Fax +4161306 1234 & 2235-0640/12/0014-0216\$38.00/0 \\
E-Mail karger@karger.com & Accessible online at: \\
www.karger.com & www.karger.com/etj
\end{tabular}

Dr. Rossella Elisei

Department of Endocrinology

University of Pisa, Via Paradisa 2

IT-56124 Pisa (Italy)

E-Mail rossella.elisei@med.unipi.it 
roid Association (ETA) Executive Committee decided to identify a task force to produce guidelines for all thyroidologists in order to provide basic information about the disease and enable best practice and referral guidelines to be more widely available.

The aim of the guidelines is to standardize and improve the quality of care for patients and families with MTC and to guide experts in the field based on in-depth evaluation of evidence. Nevertheless, the task force is aware of the limitations of the current knowledge and the lack of strong evidence in some specific topics. For these reasons, in the present guidelines there are some recommendations with a weak grade and/or a low score which are desirable to become the topics for new research able to address unresolved questions.

\section{Methods of Development of the Current Guidelines}

The methodology used to prepare these guidelines follows recommendations used for other ETA guidelines [5]. Briefly, the ETA Executive Committee launched a task force to produce guidelines for genetic screening of MTC. A chairperson was selected to lead the task force (R.E.), and 5 additional members were suggested by R.E. based on clinical expertise, representation of different disciplines possibly involved in the management of MTC patients, and representation of different European countries. The suggested members (M.A., B.C.-D., K.F.-R., V.L., and G.R.W.) were subsequently endorsed by the ETA Guidelines Board and the ETA Executive Committee, and each panel member declared whether he had any conflict of interest.

Relevant articles were identified by searching PubMed MEDLINE at PubMed (NLM) using the following search terms: medullary thyroid cancer, RET oncogene, calcitonin, calcium, RET gene carriers, MEN 2, pheochromocytoma, hyperparathyroidism, RET genetic counseling, and ethics. No limits were posed to the literature search although most recent papers were preferentially chosen for quoting. Recommendations were then developed based on the literature and expert opinion.

A preliminary document and a series of recommendations were generated by the chairperson and then critically reviewed by the members of the task force. The recommendations agreed upon by the panel would be based on a consensus of the panel. Task force deliberations took place mostly through electronic communication.
The ETA executive committee elected to rate the recommendations according to the system developed by the Grading of Recommendations, Assessment, Development, and Evaluation Group. The strength of a recommendation (SOR) is indicated by a score 1 or 2 . Score 1 indicates a strong recommendation (for or against). In contrast, score 2 indicates a weak recommendation or a suggestion that may not be appropriate for every patient, depending on the context, patient values, and preferences. Grading the quality of the evidence (QOE) takes into account study design, study quality, consistency of results, and directness of the evidence. The QOE is indicated by plus signs at 3 levels. Each recommendation is preceded by a description of the evidence.

\section{Medullary Thyroid Cancer}

MTC is a well-differentiated thyroid tumor that maintains the biochemical and pathological features of the parafollicular or calcitonin (Ct)-producing $\mathrm{C}$ cells from which it derives $[6,7]$. Its origin makes it a separate entity from the other differentiated thyroid carcinomas.

The overall frequency of MTC is not well established. Its prevalence represents $5-10 \%$ of all thyroid malignancies; it is present in $0.4-1.4 \%$ of all thyroid nodules and in less than $1 \%$ of thyroid glands at autopsy. The clinical presentation of MTC occurs mainly in the fourth and fifth decades, but a wide range of ages at onset has been observed $[8,9]$.

The biological behavior of MTC is much less favorable compared to other well-differentiated thyroid carcinomas [10]. A 10 -year survival rate of about $50 \%$ has been reported in several series of patients with MTC. The most important prognostic factor is tumor stage at diagnosis. Both cure and survival rates of patients are improved by early diagnosis, particularly when the tumor is confined to the thyroid gland without evidence of invasion or local or metastatic spread $[11,12]$.

Two different forms of MTC are recognized: the sporadic form, which accounts for about $75 \%$ of cases, and the hereditary or familial form accounting for the remaining 25\%. Males and females are affected equally by MTC both in the sporadic form and in the hereditary form. In contrast, only the hereditary form affects children and, generally, the most aggressive disease occurs in the youngest affected children [13-15].

In hereditary cases, MTC is one of the components of multiple endocrine neoplasia type 2 (MEN 2) syndrome, an autosomal dominant inherited syndrome with a vari- 
Table 1. Different phenotypes in the three MEN 2 syndromes

\begin{tabular}{lccccccc}
\hline & MTC & PHEO & PHPT & CLA & Neuromas & Megacolon & Marfanoid habitus \\
\hline MEN 2A & $98 \%$ & $50 \%$ & $25-30 \%$ & $10-15 \%$ & 0 & 0 & 0 \\
MEN 2B & $98 \%$ & $45 \%$ & 0 & 0 & $100 \%$ & $60 \%$ & $100 \%$ \\
FMTC & $100 \%$ & 0 & 0 & 0 & 0 & 0 & 0 \\
\hline
\end{tabular}

able phenotype displaying an age-related penetrance $[16$, 17]. Three different hereditary syndromes are recognized on the basis of the involved organs: (a) MEN 2A when MTC is associated with pheochromocytoma (PHEO) and/or primary hyperparathyroidism (PHPT) resulting from multiple parathyroid gland hyperplasia and/or adenomas [18]; (b) MEN 2B when MTC is associated with PHEO, mucosal neuromas, and ganglioneuromatosis [19], and (c) familial MTC (FMTC) when the inheritable MTC is apparently isolated and not associated with other endocrine neoplasias [20] (table 1). Good correlation between the three different phenotypes and specific genotypes has been described.

MTC in MEN 2 index cases usually presents as nodular thyroid disease and is similar to the presentation of sporadic MTC, with the exception that in MEN 2 the disease is usually bilateral, multicentric, and very frequently associated with $\mathrm{C}$ cell hyperplasia $(\mathrm{CCH})[21,22]$. The clinical course of MTC varies considerably in the three syndromes: the disease is indolent in the majority of patients with the FMTC, variable in severity in patients with MEN 2A, and usually more aggressive in MEN 2B, with affected patients rarely surviving beyond adolescence before the introduction of genetic testing, while in recent years longer survival rates have been observed due to a more precocious diagnosis which leads to early thyroidectomy $[17,23]$.

Between 10 and 30\% of patients with MEN 2A develop hyperplasia or multiple adenomas of the parathyroid glands and PHPT during the third or fourth decade of life. The clinical features are similar to those in patients with hyperparathyroidism resulting from sporadic parathyroid adenomas, and frequently patients are asymptomatic [24]. PHPT has only rarely been reported in MEN 2B [19].

Approximately $50 \%$ of MEN 2A and $40-45 \%$ of MEN 2B patients develop PHEO, which share the same characteristics in both syndromes. In contrast to sporadic PHEO, the adrenal tumors occurring in MEN 2 syndromes are usually bilateral and multicentric. However, the two adrenal glands are rarely simultaneously involved and a mean period of 10 years may elapse before development of a tumor in the contralateral adrenal.

The MEN 2B syndrome is characterized by the presence of mucosal neuromas, which are located mainly on the distal tongue and subconjuntival areas, and ganglioneuromas affecting the gastrointestinal tract. MEN 2B patients are recognized easily at physical examination by the typical marfanoid habitus characterized by thin and long limbs and digits together with pectus excavatum [25]. Thickened lips and eyelids are frequently observed in the presence of mucosal neuromas and are usually clearly evident. Unfortunately, these stigmata only develop after the first few years of life and, quite often, they are recognized too late. Conversely, gastrointestinal disorders due to neuromas throughout the gastrointestinal tract, including obstructive symptoms, cramping, and diarrhea, are frequently observed in early childhood.

An association with cutaneous lichen amyloidosis (CLA), a characteristic pigmented and itchy skin lesion specifically localized in the interscapular region of the back, has been reported in less than $10 \%$ of MEN 2A families $[26,27]$. When present, CLA is almost invariably diagnostic of MEN 2A and may be considered pathognomonic.

\section{Recommendation 1}

(a) Both the personal and the familial medical history should be investigated carefully in all patients with MTC in order to identify familial disease. The identification of MTC or other tumors, including PHEO (especially if bilateral) or PHPT (especially if multiglandular), in other members of the family will be highly suggestive of a hereditary form $(\mathrm{QOE}=+++$; $\mathrm{SOR}=$ score 1$)$.

(b) If the diagnosis of MTC is made preoperatively, apparently sporadic MTC patients must be investigated for the presence of RET gene mutations (see the following paragraph) and, if positive, PHEO should be excluded by measuring 24-hour urinary catecholamine or, preferably, metanephrine concentrations. PHPT should be evaluat- 
ed by determining the serum calcium concentrations, either by directly measuring calcium ions or by calculating the real concentration with the following formula: total calcemia $+[(4-$ serum albumin concentration $) \times 0.8]$. If the calcium concentration is determined to be increased, serum PTH should be measured and, if elevated, 25-hydroxyvitamin $\mathrm{D}_{3}$ levels should be determined to exclude secondary hyperparathyroidism $(\mathrm{QOE}=++$; $\mathrm{SOR}=$ score 1$)$.

(c) If the RET mutational status cannot be obtained before surgery, the 24-hour urinary catecholamine and metanephrine measurements should be necessarily performed to exclude PHEO biochemically prior to surgery $(\mathrm{QOE}=++; \mathrm{SOR}=$ score 1$)$.

(d) If a PHEO is identified, the adrenal tumor should be removed before surgical treatment of MTC. Treatment with alpha and beta adrenergic blocking agents is essential to prepare patients for surgery and must be continued during surgery $(\mathrm{QOE}=+++$; $\mathrm{SOR}=$ score 1$)$.

\section{MTC and Serum Ct}

The presence of MTC or CCH is invariably accompanied by elevated levels of serum Ct, produced and secreted by both normal and malignant $C$ cells $[7,28]$. Serum $\mathrm{Ct}$ is a very sensitive and specific marker of MTC [29] although some rare pathological conditions can be accompanied by increased levels of serum Ct [28]. Moreover, both autoimmune thyroiditis and small papillary thyroid cancer can be associated with $\mathrm{CCH}$ and then with hypercalcitoninemia. Stimulation tests, either with pentagastrin or with calcium [30,31], are useful to discriminate, with some limitations, Ct production due to MTC from Ct production due to other conditions.

Serum Ct in the management of RET mutated gene carriers (GC) is, however, less affected by the above mentioned problems since this is a selected population prone to developing MTC and any value of serum $\mathrm{Ct}$ above the normal range should be regarded as suggestive of the presence of CCH/MTC [32]. In this regard it is worth noting that a positive relationship between the serum levels of basal Ct and tumor size has been recognized for MTC $[33,34]$. In particular, there has never been a description of a tumor bigger than $0.5 \mathrm{~cm}$ and lymph node metastases if basal Ct levels are $<30-60 \mathrm{pg} / \mathrm{ml}$ [32-35]. These last values vary in different studies and each institution should find its own Ct cutoff able to discriminate $\mathrm{CCH}$ or intrathyroid micro-MTC from bigger tumors that can be associated with lymph node metastases.

2012 ETA Guidelines for RET Genetic Screening
Based on this evidence, it is conceivable to use basal serum $\mathrm{Ct}$ as a guide to decide if it is time for thyroidectomy for GC or if it can be postponed [32]. In particular, GC with basal serum Ct in the normal range or less than the institutional cutoff can avoid central neck dissection which significantly increases the risk of surgical complications [36].

In GC with an intermediate-high risk level RET mutation, a stimulation test could be useful to ensure safe planning of the thyroidectomy as soon as the test becomes positive and the basal Ct is still in the normal range. The definition of positivity of a stimulation test is still a matter of discussion, but in GC any serum Ct peak value after stimulation should be regarded with suspicious since it is often indicative of $\mathrm{CCH}$ already developed [32].

Unfortunately, several technical problems affect the interpretation of serum Ct values: (a) assays are not always comparable and different values of $\mathrm{Ct}$ can be obtained when the same serum is measured with different assays [37]; (b) some assays are affected by interference due to heterophilic antibodies that can determine a falsepositive result [38]; (c) normal ranges vary in different assays, and (d) basal Ct levels in children are still being debated $[39,40]$.

Since serum Ct determination is useful in the management of GC and it is acquiring the role of a decision-making element, it is recommended that centers taking care of GC have experience also in interpreting both basal and stimulated serum Ct.

\section{Recommendation 2}

(a) Basal serum Ct values higher than the upper limit of the normal range should be considered as 'positive'. Each institution should have its normal range $( \pm S D)$ calculated by measuring serum $\mathrm{Ct}$ in a relatively large group of subjects with no thyroid diseases. Age and sex should be taken into consideration because normal ranges can vary according to these parameters $(\mathrm{QOE}=+$; $\mathrm{SOR}=$ score 1$)$.

(b) To be compared, serum Ct values should be always measured in the same laboratory with the same assay in MTC patients and in GC in follow-up (QOE = ++; $\mathrm{SOR}=$ score 1).

(c) An institutional Ct cutoff should also be calculated to identify the $\mathrm{Ct}$ value able to discriminate $\mathrm{CCH} / \mathrm{micro}$ MTC from bigger tumors and a higher risk of having neck lymph node metastases $(\mathrm{QOE}=++$; $\mathrm{SOR}=$ score 2$)$.

(d) In RET GC even a slight increase in serum Ct after stimulation should be regarded as strongly suggestive of 


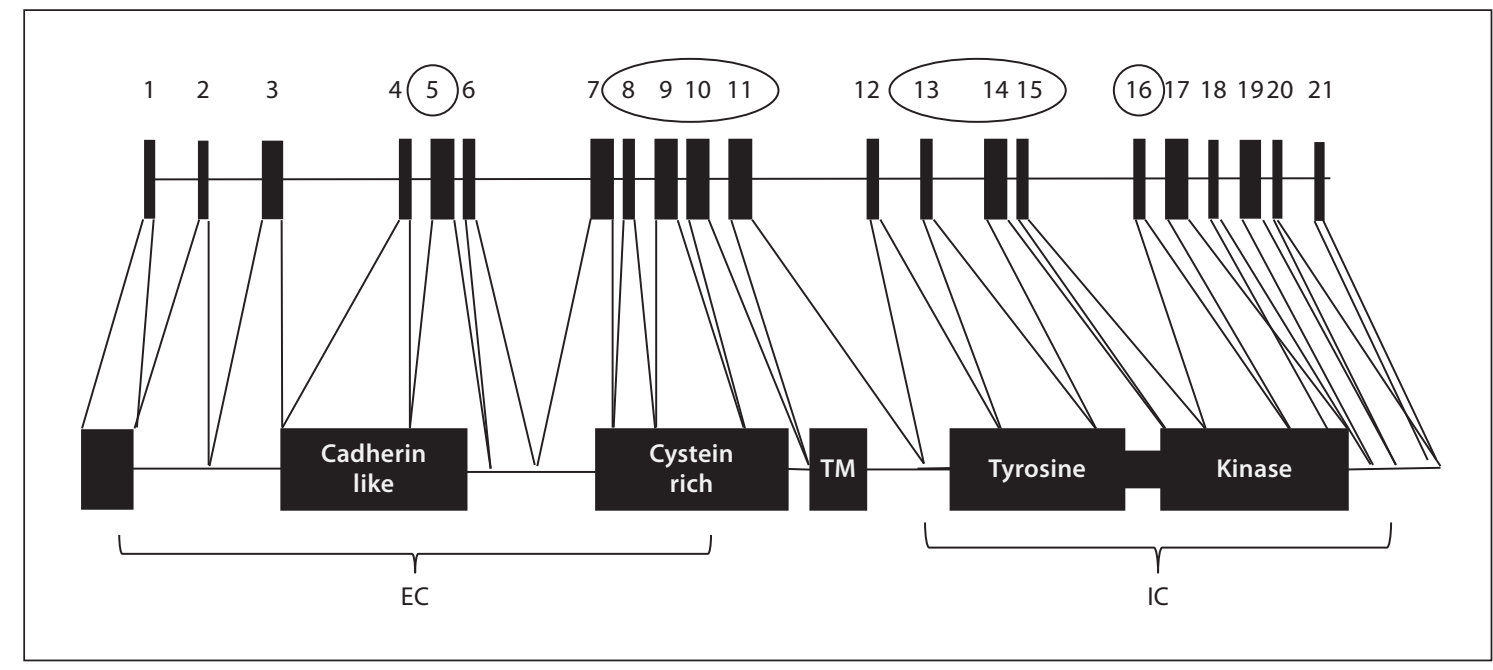

Fig. 1. Schematic representation of the RET oncogene. The 21 exons are represented and the most common mutated codons are indicated with a circle. $\mathrm{EC}=$ Extracellular domain; TM = transmembrane region; IC = intracellular domain.

the presence of $\mathrm{CCH}$ or micro-MTC $(\mathrm{QOE}=++$; $\mathrm{SOR}=$ score 2).

(e) Centers with no experience in interpreting serum $\mathrm{Ct}$ and/or pediatric surgery should refer GC to specialist centers with experience to offer the best care $(\mathrm{QOE}=$ +++ ; SOR $=$ score 1 ).

\section{RET Oncogene Mutations}

The RET proto-oncogene comprises 21 exons located on chromosome 10q11-2 and encodes a tyrosine kinase transmembrane receptor (fig. 1). The receptor is composed of an extracellular domain, with a distal cadherinlike region and a juxta-membrane cysteine-rich region, a transmembrane domain, and an intracellular domain with tyrosine-kinase activity (TK) [41]. The ret tyrosine kinase receptor is expressed in a variety of neuronal cell lineages including the thyroid $\mathrm{C}$ cells and adrenal medulla [42].

Under physiological conditions, ligand-induced dimerization of the ret protein is required for receptor activation. Four different ligands that bind ret have been identified: the glial cell line-derived neurotrophic factor (GDNF), neurturin (NTN), persepin (PNS), and artemin (ART). The ligand binding interaction is mediated by ligand-specific coreceptors including GFR $\alpha$-1, the co-receptor for GDNF [43].
In 1987, genetic linkage analysis localized the MEN2 gene locus to the centromeric region of chromosome 10 $[44,45]$. Two years later, the RET oncogene was discovered and localized on chromosome 10 [46]. In 1993, two independent groups reported that activating germline point mutations of the RET proto-oncogene are causative events in MEN 2A and FMTC $[47,48]$. One year later, MEN 2B was associated with germline RET proto-oncogene mutations [49].

Several in vitro and in vivo studies have demonstrated that $R E T$ oncogene mutations result in constitutive and ligand-independent dimerization of mutant ret proteins. Constitutive activation of ret induces auto-phosphorylation of the TK domain and continuous activation of downstream signaling pathways leading to uncontrolled cell proliferation and malignant transformation (i.e. gain-of-function mutations) [41].

More than 145 germline RET mutations have been reported. The most common are localized in exons 5, 8, 10, $11,13,14,15$, and 16 , although it cannot be excluded that some rare mutations may occasionally occur in other regions of the gene. In recent years several RET mutations with low transforming activity have also been identified. In these cases, malignant transformation of $\mathrm{C}$ cells only occurs in homozygous individuals or in the presence of compound heterozygous mutations [50]. In other cases, rare germline RET mutations have been identified in association with MTC in individual patients with no other clinically affected relatives and characterized by a very 
low or null transforming activity. For these reasons, their causative involvement in malignant transformation has been questioned [51-53].

Several RET gene polymorphisms have been also reported both in affected MTC patients and in normal subjects. It remains controversial whether some of these polymorphisms have a higher prevalence in MTC compared to normal individuals and if they play any role in susceptibility to the development of MTC [54-58].

Up-to-date information on the different RET mutations identified in MEN 2 syndromes can be accessed via the following links: www.hgmd.cf.ac.uk and www.arup. utah.edu/database/MEN2.

As in other genetic disorders, screening for RET mutations can be performed using different techniques including direct sequencing analysis, enzymatic restriction analysis, pyrosequencing, ARMS, etc. [59]. Individual laboratories adopt their own preferred method to perform mutation analysis based on available experience and equipment. The most important difference among the techniques relates to the sensitivity of each method [60]. While the functional limit of the most traditional direct sequencing is $20 \%$ (i.e. a mutation must be present in approximately $20 \%$ of the sample to be readily detected), it decreases up to $1 \%$ in the ARMS method. However, for germline RET genetic screening, in which at least $50 \%$ of alleles are affected, the functional limit of the direct sequencing is acceptable and it is not necessary to adopt more sensitive approaches.

\section{Recommendation 3}

(a) Blood (2-5 ml) should be collected in EDTA for DNA extraction. Samples not immediately processed should be kept at -20C. PCR amplification with specific primers, both forward and reverse, for exons to be analyzed should be performed and then submitted to sequencing analysis. The result should be confirmed either by repeating the direct sequence or, if applicable, by enzymatic restriction analysis possibly using a second independent blood sample of the patient. Once the 'familial' mutation has been discovered, either direct sequence or enzymatic restriction might be used for the search of that specific mutation in the family members $(\mathrm{QOE}=++$; SOR = score 1 ).

(b) Newly discovered RET germline mutations, not included in the published database, should not be considered immediately as causative in the development of MTC but they must be firstly analyzed for their transforming ability with in silico and in vitro tests that should be performed in specialized centers. Allele frequency analysis should also be studied in a control group of normal subjects to exclude the possibility that they may represent polymorphisms that lack functional significance $(\mathrm{QOE}=++; \mathrm{SOR}=$ score 2$)$.

(c) So far, none of the known RET polymorphisms has been demonstrated to be disease causative; thus, even if identified in the index case, they should not be further searched in family members $(\mathrm{QOE}=+++$; $\mathrm{SOR}=$ score 1$)$.

(d) If no RET mutations are found and the personal/ familial history is negative, the case can be considered as sporadic and there is no need to screen these subjects for other endocrine neoplasia. Moreover, their relatives should not undergo any biochemical or genetic screening related to MTC. Conversely, if the familial history is strongly suggestive of a hereditary form, all efforts to find an RET mutation should be made and first-degree relatives should be followed with clinical and biochemical controls (see recommendations $4 \mathrm{a}$ and $4 \mathrm{~b})(\mathrm{QOE}=+++$; $\mathrm{SOR}=$ score 1$)$.

\section{RET Oncogene and Hereditary MTC: Genotype-Phenotype Correlation}

RET germline gain-of-function mutations are inherited as an autosomal dominant trait and thus $50 \%$ of children of patients with hereditary MTC are at risk of developing MTC, whereas children who do not inherit the mutation are not at risk. In $4-10 \%$ of patients with MEN 2A or FMTC, and $95 \%$ of patients with MEN 2B, the germline RET mutation is 'de novo' as demonstrated by negative RET genetic analyses of parents [61].

A high genotype-phenotype correlation has been recognized. About $98 \%$ of patients with MEN 2A have RET mutations in the cysteine-rich extracellular domain, in particular in codons $609,611,618,620$, and 634 of exons 10 and 11. Mutations at codon 634 of exon 11 (mainly TGC to CGC) are the most common, accounting for $85 \%$ of MEN 2A cases [62-64]. Mutation of cysteine 634 also correlates significantly with the presence of PHEO and PHPT [62].

A specific mutation in exon 16 at codon 918 (ATG to ACG) is almost invariably associated with MEN 2B. Other rare mutations of the intracellular domain have been reported in codon 883 of exon 15 [65]. The M918T mutation is associated with a very aggressive MTC that usually develops during childhood, often only a few years after birth. At variance with MEN 2A and 2B, in FMTC the mutations are widely distributed among the 


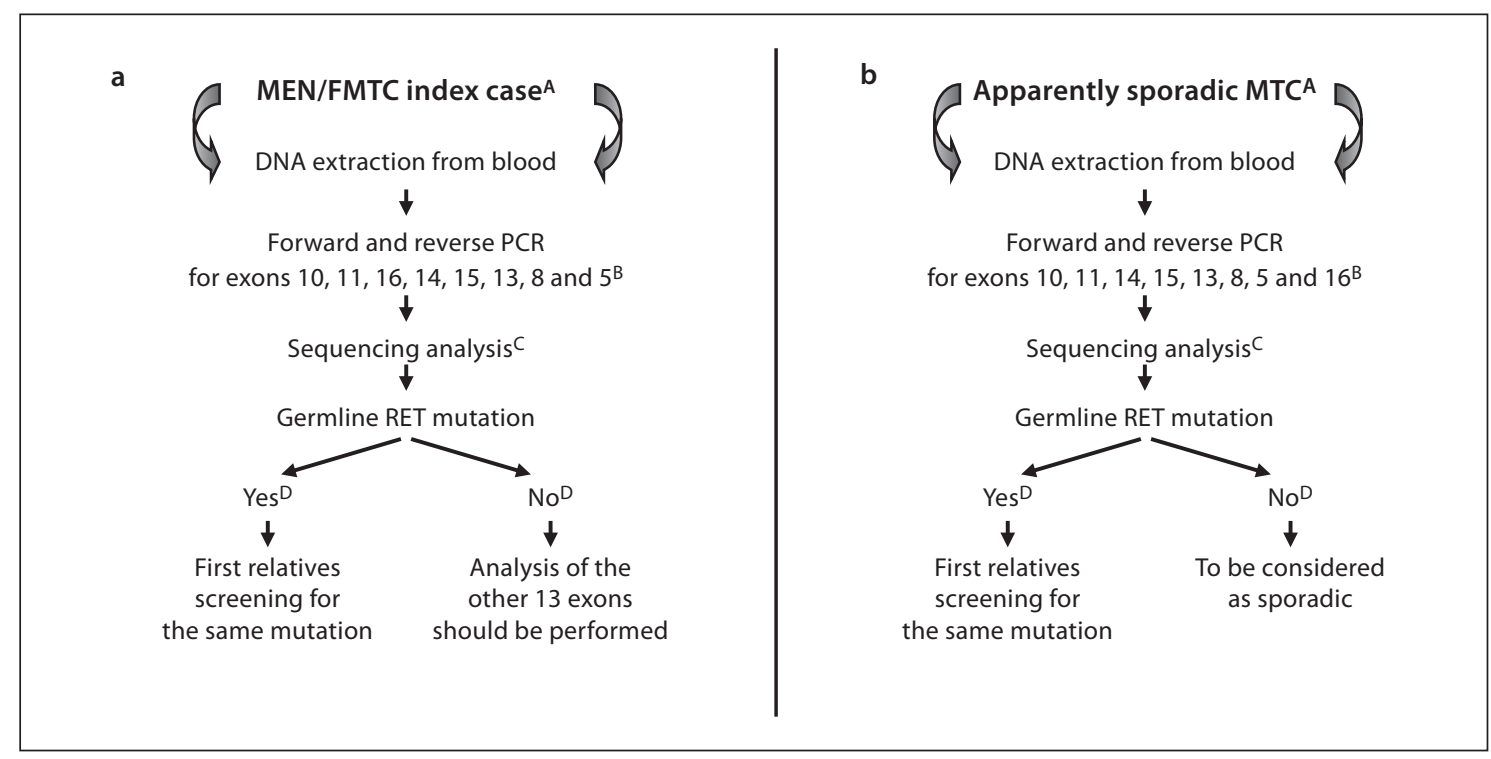

Fig. 2. Algorithm of RET genetic screening according to the frequency of RET mutations in MEN 2/FMTC index cases (a) and in apparently sporadic MTC (b). a A = The hereditary nature has been well established on a clinical basis and/or based on familial history; $\mathrm{B}=$ the order here indicated is based on the frequency of the mutations but the clinical features should also be considered, and if an MEN 2B is supposed then exon 16 should be analyzed

5 cysteine codons $609,611,618,620$, and 634 but also, and most frequently, in other noncysteine codons, such as codon 804 in exon 14, codon 891 in exon 15, and others $[23,63]$.

Although in the majority of cases a single germline RET mutation has been found both in the index case and in the affected members of the family, a few cases with a double RET mutation (i.e. at codons 804 and 904 or at codons 634 and 640) have also been described [66, 67]. Recently, a case of a triple RET mutation at codons 634, 640 , and 700 was identified [68].

Only $2-5 \%$ of MEN 2 families, mostly with the FMTC phenotype, are 'orphans' of RET mutations $[69,70]$. When no germline mutations are found in the 8 exons most frequently affected, but the familial history is strongly suggestive of a hereditary form, an effort should be made to identify a possible association with rare or unknown germline RET mutations [51-53]. For this purpose, a search for RET mutations in the remaining 13 exons, rarely but possibly affected by mutations, should be performed before defining the case as an RET-negative hereditary case. An algorithm of the screening procedure is reported in figure 2 . first; $\mathrm{C}=$ other methods may also be used; $\mathrm{D}=$ in both cases a second test should be performed in a second blood sample. $\mathbf{b} \mathrm{A}=$ Any clinical evidence and/or familial history suggesting a hereditary nature; $\mathrm{B}=$ the order here indicated is based on the frequency of the mutations; $\mathrm{C}=$ other methods may also be used; $\mathrm{D}=$ in both cases a second test should be performed in a second blood sample.

\section{Recommendation 4}

(a) Exons 5, 8, 10, 11, 13, 14, 15, and 16 should always be analyzed starting from the most likely involved in the presenting syndrome (i.e. exon 10 in MEN 2A, exon 16 in MEN 2B, etc.). DNA from MTC patients with a strong suggestion of familial disease should also be analyzed for all other uncommonly mutated exons when those listed above are negative (see table 2 for primers to be used to amplify uncommonly mutated exons) ( $\mathrm{QOE}=+++$; SOR $=$ score 1 ).

(b) Subjects belonging to the few families $(2-5 \%$ of all MEN 2/FMTC families) with clinically evident MEN 2/ FMTC features but lacking evidence of an associated germline RET mutation should be followed up annually by measurement of basal serum Ct, metanephrines, calcium, and PTH. Neck and abdomen ultrasound could also be useful although not absolutely required if biochemical tests are still negative $(\mathrm{QOE}=++$; $\mathrm{SOR}=$ score 1$)$.

(c) Once a germline RET mutation has been identified, all first-degree relatives and other relevant family members should be screened for the specific causative mutation $(\mathrm{QOE}=+++$; $\mathrm{SOR}=$ score 1$)$. 
Table 2. Set of primers used for the PCR amplification of RET exons not routinely screened

\begin{tabular}{|c|c|}
\hline Exons & Primers \\
\hline EX 1 & $\begin{array}{ll}\text { for. } & \left(5^{\prime}->3^{\prime}\right) \text { : GCACCCGCCATCCAGACCC } \\
\text { rev. } & \left(3^{\prime}->5^{\prime}\right) \text { : GAGCCGGCGGCCGCAGAAC }\end{array}$ \\
\hline EX 2 & $\begin{array}{l}\text { for. }\left(5^{\prime}->3^{\prime}\right) \text { : AGCCTTATTCTCACCATCCC } \\
\text { rev. }\left(3^{\prime}->5^{\prime}\right) \text { : ATAAGGGCGGCTTGAGGAAG }\end{array}$ \\
\hline EX 3 & $\begin{array}{l}\text { for. }\left(5^{\prime}->3^{\prime}\right) \text { : CGACTGCCTGGCAGATGT } \\
\text { rev. }\left(3^{\prime}->5^{\prime}\right) \text { : ATGGCTTGTGTCAAGGGC }\end{array}$ \\
\hline EX 4 & $\begin{array}{l}\text { for. }\left(5^{\prime}->3^{\prime}\right) \text { : TTCCCGAGGAAAGCGGCT } \\
\text { rev. }\left(3^{\prime}->5^{\prime}\right) \text { : CTAAACCGACCGAGAAAC }\end{array}$ \\
\hline EX 6 & $\begin{array}{l}\text { for. }\left(5^{\prime}->3^{\prime}\right) \text { : TGAGGAAGCAGCCAGAGCAG } \\
\text { rev. }\left(3^{\prime}->5^{\prime}\right) \text { : CCCATGTCCCTTGGCCT }\end{array}$ \\
\hline EX 7 & $\begin{array}{l}\text { for. }\left(5^{\prime}->3^{\prime}\right) \text { : TACCCTCAGGCCATTACAGG } \\
\text { rev. }\left(3^{\prime}->5^{\prime}\right) \text { : CCTGGAGCAGGCACTCAC }\end{array}$ \\
\hline EX 9 & $\begin{array}{l}\text { for. }\left(5^{\prime}->3^{\prime}\right): \text { CCACATGGGTGACAGCCT } \\
\text { rev. }\left(3^{\prime}->5^{\prime}\right): \text { GGATCCAGGTTTCCCCTACTA }\end{array}$ \\
\hline EX 12 & $\begin{array}{l}\text { for. }\left(5^{\prime}->3^{\prime}\right): \text { TCCCCTGTCATCCTCACACT } \\
\text { rev. }\left(3^{\prime}->5^{\prime}\right): \text { CCCCACCCCGGAGA }\end{array}$ \\
\hline EX 17 & $\begin{array}{l}\text { for. }\left(5^{\prime}->3^{\prime}\right) \text { : ATCTGGGCCCCCCG } \\
\text { rev. }\left(3^{\prime}->5^{\prime}\right) \text { : CCCCTCCCTTCCCAAGT }\end{array}$ \\
\hline EX 18 & $\begin{array}{l}\text { for. }\left(5^{\prime}->3^{\prime}\right) \text { : GGGCTGTCCTTCTGAGACCT } \\
\text { rev. }\left(3^{\prime}->5^{\prime}\right): \text { GGAGTCTCCCCAAGCCACT }\end{array}$ \\
\hline EX 19 & $\begin{array}{ll}\text { for. } & \left(5^{\prime}->3^{\prime}\right) \text { : TATCTAGTTGTGGCACATGGCT } \\
\text { rev. } & \left(3^{\prime}->5^{\prime}\right) \text { : GCGGTGCTAGAATCTAGTAAATG }\end{array}$ \\
\hline EX 20 & $\begin{array}{ll}\text { for. } & \left(5^{\prime}->3^{\prime}\right): \text { GGAGTTTTGCCAAGGCCT } \\
\text { rev. } & \left(3^{\prime}->5^{\prime}\right): \text { GGCCGGTAGACTTTCCATTT }\end{array}$ \\
\hline
\end{tabular}

(d) Once a germline RET mutation has been discovered, further sequencing adds little, although some cases of double or triple RET mutations have been reported. These peculiar cases would likely be missed if RET screening was stopped when the first mutation was identified. The completeness of RET gene analysis is particularly indicated when the first identified mutation is rare and with a low or null transforming ability. These rare cases should be referred to specialized tertiary centers for a complete characterization of the mutation and its relationship with the disease $(\mathrm{QOE}=++$; $\mathrm{SOR}=$ score 2).

(e) Family members negative for the mutation are not at risk for the development of MTC and their children are not at risk either. Such individuals should be reassured and do not require further investigation or follow-up $(\mathrm{QOE}=+++$; $\mathrm{SOR}=$ score 1$)$.

\section{RET Genetic Screening in Apparently Sporadic MTC}

RET mutation screening can also be useful to distinguish whether an apparently sporadic MTC is genuinely sporadic or unconsciously hereditary. Many reports indicate that $7-10 \%$ of 'apparently' sporadic forms are actually misdiagnosed hereditary cases because of the presence of a germline mutation despite a negative family history [23, 71, 72]. The majority of hereditary MTC discovered by genetic screening represents FMTC, the prevalence of which has been found to be much higher than previously reported, and nowadays FMTC is the most common form of hereditary MTC in many series [23-63].

The clinical importance of correct diagnosis of hereditary MTC is clear as it results in reclassification of the index case, the requirement for screening and follow-up to determine possible development of PHEO or PHPT, and the need for early counseling and genetic screening of relatives.

\section{Recommendation 5}

(a) All patients with either apparently sporadic or familial MTC should be screened for germline RET mutations $(\mathrm{QOE}=+++$; $\mathrm{SOR}=$ score 1$)$.

(b) Patients with apparently sporadic MTC who are negative for common germline RET mutations (i.e. exons $5,8,10,11,13,14,15$, and 16) can be considered as sporadic, with only a $0.2-0.5 \%$ probability of misdiagnosed FMTC or MEN 2. Family members can also be reassured since their risk of being affected becomes negligible. No further biochemical analysis or imaging for PHEO or PHPT is necessary in these subjects $(\mathrm{QOE}=+++$; $\mathrm{SOR}=$ score 1$)$.

\section{Other Phenotypes That Require Germline RET Mutation Screening}

Although MTC is usually the first component of MEN 2 syndromes to be diagnosed [73], either PHEO or PHPT may present first, raising the question of whether RET genetic screening should be performed in such cases. Different strategies can be adopted depending on the presenting tumor.

Bilateral PHEO: although not necessarily synchronous, up to 20-25\% of PHEO are bilateral [16]. When they are bilateral, they are almost invariably familial and several syndromes have been recognized. PHEO may occur in patients with MEN 2A and 2B, Von Hippel Lindau syn- 
drome, neurofibromatosis type I, and in familial paraganglioma/PHEO syndrome. Mutations of oncogenes such as RET, VHL, NF1, TMEM127, MAX, and SDH can all cause familial PHEO [74]. This genetic variability suggests that RET genetic screening should be prioritized to subjects with bilateral PHEO and a family history of MEN 2A or 2B or those with coexistent MTC or PHPT.

Primary hyperparathyroidism: PHPT should first be distinguished from secondary HPT, which is prevalent in patients with vitamin D deficiency [75]. The most frequent cause of PHPT is a benign single parathyroid adenoma or parathyroid gland hyperplasia. A less common cause results from multiple gland hyperplasia or parathyroid adenomas, which are present in $90 \%$ of MEN 1 cases and may be associated with MTC and PHEO in MEN 2A. Other hereditary syndromes include hereditary hyperparathyroidism-jaw tumor (HPTJT) syndrome, familial isolated hyperparathyroidism, familial hypocalciuric hypercalcemia $(\mathrm{FHH})$, and neonatal severe hyperparathyroidism (NSHPT). Mutations of MEN1 and CDKN1B genes are responsible for MEN 1 in $70-80 \%$ and about $2 \%$ of cases, respectively. HRPT2/CDC73 gene mutations are responsible for HPTJT. FHH and NSHPT represent the mildest and severest variants of $\mathrm{FHH}$, caused by heterozygous and homozygous mutations in the calcium sensing receptor (CASR) gene, respectively [76]. Also in this situation, the heterogeneity of causes of PHPT and the several genetic alterations that can result in the different syndromes strongly suggests that RET genetic screening should be performed only in cases of PHPT clearly suggestive of MEN 2A, either by the presence of a positive family history or by the presence of associated PHEO, MTC, or CLA.

Cutaneous lichen amyloidosis: although only $10 \%$ of MEN 2A patients are characterized by the presence of a cutaneous pruriginous and thickened lesion in the intrascapular back region, this phenotype is very suggestive of MEN 2A [26, 27]. When appropriately investigated, patients usually report that other members of the family have the same itchy lesion. With the exception of one family with a V804M RET mutation, CLA has been described only in MEN 2A families due to a codon 634 RET mutation in exon 11 [77].

Hirschsprung disease: the RET oncogene is also involved in the pathogenesis of Hirschsprung disease, which is characterized by the congenital absence of the enteric ganglion cells of the colon, or part of the colon, so that the affected segment fails to relax, causing functional obstruction [78]. Hirschsprung disease may be either sporadic or familial. Several germline RET mutations, mainly located in the extracellular domain, have been identified in $20-40 \%$ of individuals with Hirschsprung disease, with higher frequencies observed in familial cases [79]. In contrast to gain-of-function activating RET mutations that cause MTC, the loss-of-function RET mutations in Hirschprung disease result in inactivation of the mutant ret protein. However, some activating RET mutations, which are almost exclusively localized in exon 10, have been found in patients with both Hirschsprung disease and MTC; such dual function mutations are known as 'RET Janus mutations' [80, 81]. In one recent series, Hirschsprung disease was present in 20/267 informative carriers $(7.5 \%), 2 / 37(5.4 \%)$ in those with mutations in codon $609,0 / 44$ in codon $611,1 / 56(1.8 \%)$ in codon 618 , and 17/130 (13.1\%) in codon 620 [82].

\section{Recommendation 6}

(a) Patients with bilateral PHEO should be considered for RET genetic screening when other MEN 2A endocrinopathies (MTC and/or PHPT) or CLA are present in the same subject or if a family history of MEN $2 \mathrm{~A}$ or $2 \mathrm{~B}$ is present. The screening becomes mandatory if the basal serum $\mathrm{Ct}$ is above the normal range, independently of the presence of other MEN 2A endocrinopathies (QOE $=++$; SOR $=$ score 1 ).

(b) Patients with multiple adenomatosis of the parathyroid glands and PHPT should be considered for RET genetic screening if other MEN 2A endocrinopathies (MTC and/or PHEO) or CLA are present in the same subject or if a family history of MEN 2A is present. Also in this case, RET genetic screening must be performed if basal serum Ct levels are above the normal range, even if no other MEN 2A endocrinopathies are diagnosed (QOE $=++$; SOR $=$ score 1 ).

(c) Subjects with CLA should be investigated clinically and should undergo genetic testing for MEN 2A. In particular RET codon 634 in exon 11 should be analyzed $(\mathrm{QOE}=+++$; $\mathrm{SOR}=$ score 1$)$.

(d) Patients with Hirschsprung disease should have RET genetic screening for mutations involved in Hirschsprung disease, but analyses performed specifically to investigate an association with MEN 2 should be limited to exon $10(\mathrm{QOE}=+++$; $\mathrm{SOR}=$ score 1$)$.

\section{Gene Carriers}

Until 1993, basal and stimulated serum Ct were measured periodically in relatives of patients with hereditary MTC to identify and treat positive cases early [28, 83]. After 1993, when RET activating mutations were demon- 
strated to be causative in MEN 2 [47-49], RET genetic screening was introduced for early identification of GC who are at risk of developing MTC [62]. Prophylactic thyroidectomy was immediately proposed as a definitive cure for GC at risk of developing MTC [84].

Over the years, it has been demonstrated that among the causative RET mutations there are some including M918T, most typically found in MEN 2B, which are associated with very aggressive disease whereas others including C634A, most commonly present in MEN 2A, are less so. Furthermore, a different biological behavior, characterized by reduced aggressiveness and an older mean age at diagnosis, has been described for mutations in noncysteine codons that are mainly associated with FMTC [63]. A rather heterogeneous group is represented by RET mutations in codon 10. The results of a multicenter study of 340 patients carrying exon 10 mutations show differences in the aggressiveness of MTC depending on the mutated codon [82]. For this reason, guidelines for the diagnosis and management of MTC and other components of MEN 2 have reached only a weak consensus concerning the management of GC with mutations in exon 10. However, there is a rather clear correlation between the decreasing order of the codon number (e.g. 620, 618, 611, and 609) and an earlier age at manifestation (table 3), more advanced tumor stage at presentation, and decreased chance of cure.

According to the aggressiveness and age of onset of MTC, 4 different risk levels for RET mutations have been distinguished (A, lowest, to $\mathrm{D}$, highest) and proposed as a guide to plan surgical treatment of GC [1] while the relationship between serum Ct levels and MTC development has been almost completely disregarded. In this regard, it is important to note that progression from a normal basal serum Ct level to an elevated value was used successfully for several years as a method to identify MTC patients with early stage and premetastatic disease [85]. Recently, several groups reported that basal Ct levels of less than $30-60 \mathrm{pg} / \mathrm{ml}$ are associated with early disease in which the tumor is still intrathyroid, usually $<1 \mathrm{~cm}$ in diameter, and with no evidence of lymph node metastasis [32, 35]. Taking into account these observations and the high sensitivity of serum Ct as an MTC marker, the time of surgical treatment can be personalized and planned safely according to the serum $\mathrm{Ct}$ values found at the periodic annual control, independent of the type of RET mutation and its associated level of risk [73] (fig. 3). This approach has two significant advantages: (1) the later medicalization and (2) the reduction of the prevalence of surgical complications, especially in children, who are at higher risk of both nerve palsy and hypoparathyroidism (from 6
Table 3. Earliest reported age of onset of different endocrine neoplasias in the most common RET mutations associated with MEN 2A or MEN 2B

\begin{tabular}{llll}
\hline & \multicolumn{2}{l}{ Age, years } & \\
\cline { 2 - 4 } RET mutation & MTC & PHEO & HPTH \\
\hline Cys 609 & 5 & 22 & \\
Cys 611 & 7 & 30 & \\
Cys 618 & 7 & 29 & 41 \\
Cys 620 & 6 & 22 & \\
Cys 630 & 1 & 32 & 32 \\
Cys 634 & 1.1 & 12 & 10 \\
Glu768 & 22 & 59 & \\
Leu 790 & 10 & 28 & 38 \\
Tyr 791 & 21 & 38 & \\
Val804 & 12 & 33 & \\
Met918 & 0.5 & 12 & \\
\hline
\end{tabular}

to $17 \%$ in different series [86-88]) than adults (from 0.7 to $1.5 \%[89,90])$. It is worth saying that this strategy is particularly recommended in centers with little experience in pediatric thyroidectomy but it implies a high compliance of GC and, when children are still young, of their parents to the control schedule. However, it is not desirable for treatment and management of these cases to continue in nonspecialized departments and they should best be referred to centers with substantial experience on this specific topic.

The possibility to develop PHEO should also be taken into consideration in RET GC. The penetrance and the age of diagnosis of PHEO among different MEN 2 kindreds depends on specific RET germline mutations (tables 1,3 ), with a $50 \%$ occurrence in codon $634,22 \%$ in codon $618,9 \%$ in codon 620 , and $4 \%$ in codon 609 , rarely in patients with exon 14 and 15 mutations, but in $40 \%$ of MEN 2B patients with codon 918 mutation. As far as the possibility to develop PHPT is concerned, this is mainly present in patients with MEN 2A syndrome and in particular in those with a mutation in codon 634 [62] who can be hypercalcemic at an early age (tables 1,3 ).

\section{Recommendation 7}

(a) Once a GC has been identified, the basal serum Ct should be measured. If the basal Ct is already elevated (e.g. above the upper level of the normal range in that institution) the GC should be referred immediately for total thyroidectomy. Central compartment lymphadenectomy can be avoided in GC with basal Ct values $<30-60 \mathrm{pg} / \mathrm{ml}$ 
Fig. 3. Algorithm of treatment of RET mutated GC.

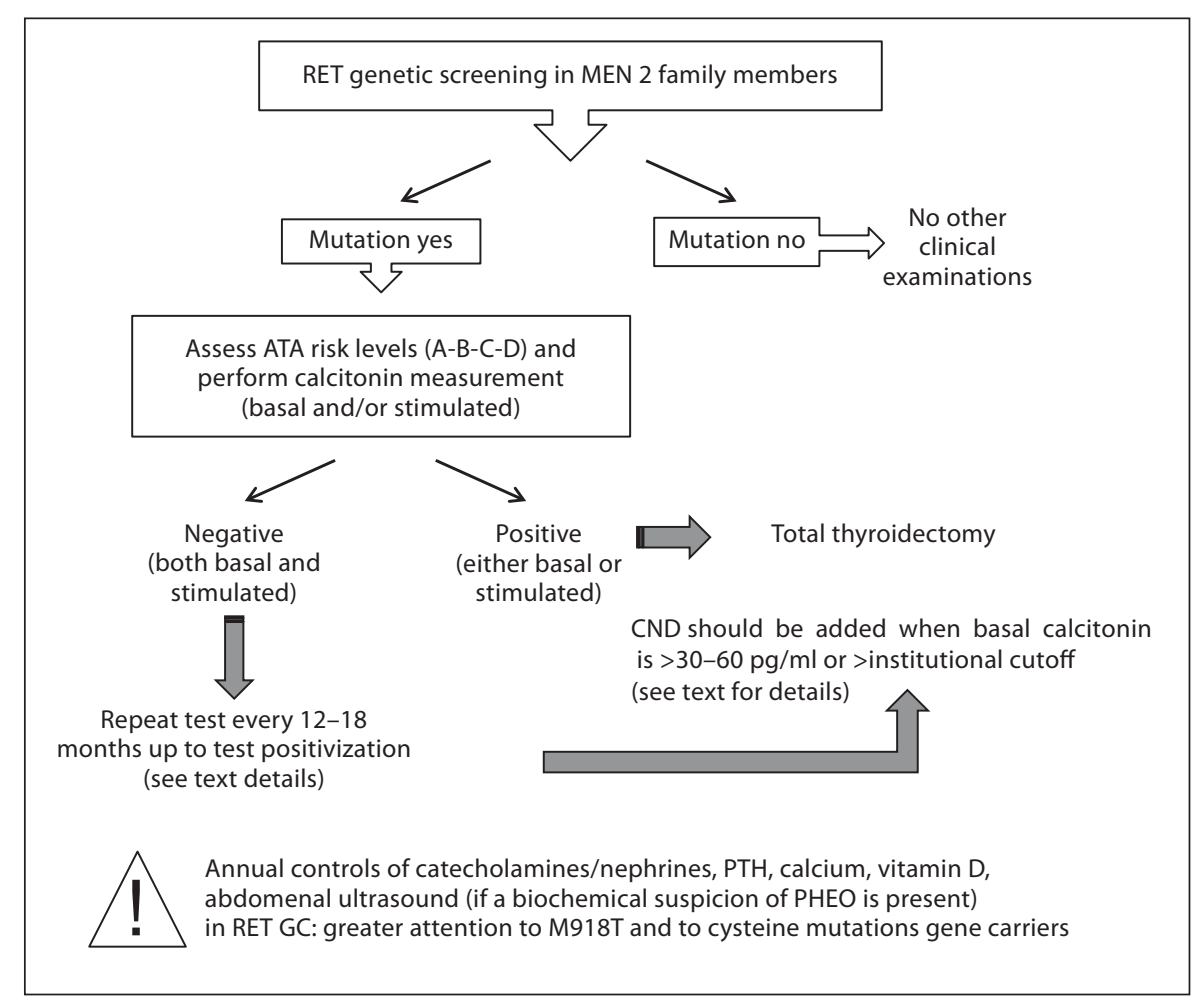

or below the institutional cutoff $(\mathrm{QOE}=+++$; $\mathrm{SOR}=$ score 2).

(b) If the basal serum $\mathrm{Ct}$ is still in the normal range, thyroidectomy could be postponed to a later time. In this situation, a stimulation test (either with pentagastrin or calcium) is indicated in GC carrying intermediate-high risk mutations ( $\mathrm{C}$ and $\mathrm{D}$ risk levels) to obtain a very early identification, when only $\mathrm{CCH}$ is developed, of an MTC that could be aggressive. However, if the stimulated $\mathrm{Ct}$ level does not rise above the upper limit of the normal range, thyroidectomy can be further postponed and the stimulation test repeated after 12-18 months. For very low risk mutations, such as those of the A risk level, only basal serum Ct can be monitored every 12-18 months $(\mathrm{QOE}=+++$; $\mathrm{SOR}=$ score 2$)$.

(c) Although some MEN 2B GC with serum Ct $<30-$ $60 \mathrm{pg} / \mathrm{ml}$ and no MTC have been recently reported, the aggressiveness of the thyroid tumor in this syndrome is so high that there is still a need to recommend performance of a thyroidectomy as soon as possible after diagnosis $(\mathrm{QOE}=+++$; $\mathrm{SOR}=$ score 1$)$.

(d) Central neck lymph node dissection should always be performed together with total thyroidectomy if the basal serum Ct is above $30-60 \mathrm{pg} / \mathrm{ml}$ or above the institutional cutoff $(\mathrm{QOE}=++$; $\mathrm{SOR}=$ score 2$)$. (e) Depending on the genotype, biochemical screening for PHEO should be performed beginning at the age of approximately 8 years in GC with mutations suggestive for MEN 2B and mutations in exons 10 and 11, and by the age of approximately 20 years in GC with mutations in the other codons. The measurement of catecolammines and metanephrines should be performed every $12-18$ months $(\mathrm{QOE}=++$; $\mathrm{SOR}=$ score 2$)$.

(f) Because of high risk to the fetus and the mother, women with an RET mutation associated with MEN 2 should be screened for PHEO before pregnancy (QOE = ++ ; SOR $=$ score 1 ).

(g) Biochemical screening for PHPT should be performed annually in MEN2A GC, particularly in those with an RET mutation in codon $634(\mathrm{QOE}=++$; $\mathrm{SOR}=$ score 1$)$.

\section{Ethics}

RET genetic screening should be accompanied by genetic counseling involving a specialist clinical geneticist and expert endocrinologist, who are qualified to provide accurate assessment of disease inheritance, penetrance, and risk. Additional support from a specialist psychologist may be necessary for GC individuals who may need 
to address issues arising from the knowledge of disease carrier status. Informed consent must be signed by patients before discussion regarding $R E T$ status. In particular, it is necessary to discuss the $50 \%$ risk of disease inheritance in first-degree relatives of index cases with MTC. This issue is controversial because it remains unclear who should be responsible to inform the relatives of their potential disease risk.

Several medical associations strongly support the concept that the genetic tests are undoubtedly confidential and that the duty to inform the relatives should be a moral obligation of the patient [91, 92]. This specific issue should be discussed in the context of informed consent. However, under special circumstances such as, for example, when familial relationships have been disrupted or when the paternity has not been recognized etc., direct contact between the physician responsible for the genetic test and at-risk relatives should be allowed regardless of patient consent [93].

An additional and key ethical consideration is the consent of GC children. Consent for children should be undertaken by either parents or legal guardians, who should also take responsibility to inform the child of his/her genetic status in the future [94]. If this responsibility is refused or if parents are separated or divorced, or if they are not married and the individual carrying the RET mutation does not wish to reveal his or her status to the partner or child, a legal guardian should be appointed until the child reaches 18 years of age.

Despite all of these suggestions, clinicians involved in this specific issue should take into consideration that each country has its own ethical regulations that should be followed strictly, and clinicians are encouraged to be fully informed of the laws of consent and medical ethics.

\section{Recommendation 8}

(a) Genetic counseling should be always offered to MTC patients who undergo a genetic screening. A dedicated and expert multidisciplinary team should be available in centers involved in the management of MTC/ MEN 2 patients. The team should possibly include a psychologist, an endocrine surgeon, an endocrinologist/ MEN 2 expert, and a geneticist. Sometimes the same individual is both the medical geneticist and the MEN 2 expert $(\mathrm{QOE}=+$; $\mathrm{SOR}=$ score 1$)$.

(b) Informed consent should be signed by the patient for him/herself with which he/she also takes the responsibility to inform the relatives of their risk if his/her genetic testing is positive $(\mathrm{QOE}=+$; $\mathrm{SOR}=$ score 2$)$. (c) The RET genetic screening result should be communicated with an official notification reporting the type of RET mutation, the most frequently associated phenotype if known, and the A,B,C, or D level of risk of the mutation $(\mathrm{QOE}=+$; $\mathrm{SOR}=$ score 1$)$.

(d) When an RET-positive patient refuses to inform the relatives of their risk of disease inheritance, the physician should be permitted to undertake notification or the local medical ethics committee should be involved. Nevertheless, since there are differences in various countries, this decision must follow the law of each specific country $(\mathrm{QOE}=+$; $\mathrm{SOR}=$ score 2$)$.

(e) Both parents of children below 18 years of age should sign informed consent before their child undergoes genetic testing. If for any reason one or both parents do not or cannot sign the consent form, a legal guardian should be involved. Either the parents or the legal guardian should take the responsibility to inform the child of his/her RET mutational status when he/she is 18 years old $(\mathrm{QOE}=+$; $\mathrm{SOR}=$ score 2$)$.

\section{RET Oncogene Somatic Mutations in Sporadic MTC}

Somatic RET mutations are found in about $40 \%$ of sporadic cases of MTC mainly consisting of an M918T mutation in exon 16, which is the same mutation that also occurs in MEN 2B [95]. Other RET somatic mutations and some small deletions have been reported in 'hot spot' regions in exons 10 and 11 [96], while other codons causing familial disease have never been found to be involved as somatic mutations [97]. Several studies indicate that MTC patients with somatic RET mutations have an advanced stage at diagnosis and a poorer prognosis than those with no evidence of RET mutation [98-101]. A positive correlation between the presence of a somatic $R E T$ mutation and a higher percentage of cells with a greater mitotic activity has been also described [102].

In the last 5 years, new target therapies with tyrosine kinase inhibitors have been investigated, and some are still under study for their potential role in the treatment of advanced metastatic MTC [103]. Some of these drugs are active against both RET and other tyrosine kinase receptors. Recently, the positive results of a phase 3 study with vandetanib (or ZD6474) were published. In this study it was demonstrated that MTC patients with a somatic M918T mutation were better responders [104].

According to this evidence, knowledge of the somatic RET mutation in MTC can be useful for both prognostic purposes and future therapeutic strategies. Recently, 


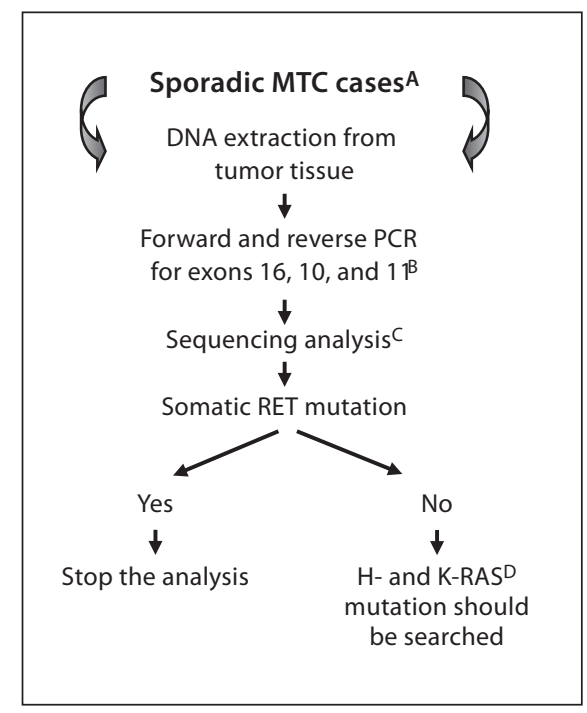

Fig. 4. Algorithm of somatic RET screening in sporadic MTC. $\mathrm{A}=40-50 \%$ of sporadic MTC harbor a somatic RET mutation; $\mathrm{B}=$ these are the exons in which the majority of somatic mutations have been found; the other exons can be analyzed for research purposes; $\mathrm{C}=$ other methods may also be used; in this case a more sensitive method could be better; $\mathrm{D}=\mathrm{N}$-RAS mutations are virtually absent in MTC.

some reports demonstrated that sporadic MTC tumors negative for somatic RET mutations can harbor a somatic RAS mutation, mainly H- or K-RAS [105-107]. Patients with MTC associated with somatic RAS mutations may represent less aggressive cases but further studies are required to confirm this preliminary observation [106]. In summary, the most common RET and RAS somatic mutations should be investigated in tumor tissue samples from patients lacking a germline mutation (fig. 4).

\section{Recommendation 9}

(a) Whenever possible, DNA should be extracted from tumor tissue in patients with sporadic MTC and sequenced for the most common M918T mutation in the first instance. If negative, other somatic RET mutations located in hot spot codons, particularly in exons 10 and 11 , and $\mathrm{H}$ - and K-RAS mutations should also be investigated to better characterize the molecular profile of the tumor $(\mathrm{QOE}=+++$; $\mathrm{SOR}=$ score 2$)$.

(b) An official notification should be reported, either in the pathology report or as an independent document, so that the information will be available for future therapeutic purposes. Other than the detected somatic RET or $R A S$ mutation, the RET and RAS exons analyzed and found to be negative should also be indicated $(\mathrm{QOE}=++$; $\mathrm{SOR}=$ score 2 ).

\section{Acknowledgements}

We thank all ETA members who provided suggestions and constructive criticisms. Particularly, we thank Dr. Furio Pacini for his invaluable contributions and remarkable support.

\section{Disclosure Statement}

The authors have nothing to disclose.

\section{References}

1 Kloos RT, Eng C, Evans DB, Francis GL, Gagel RF, Gharib H, et al: Medullary thyroid cancer: management guidelines of the American Thyroid Association. Thyroid 2009;19:565-612.

2 Tuttle RM BD, Byrd D, Dilawari RA, Doerthy GM, Duh Q, Ehya H, Farrar WB, Haddad RI, Gallagher L, Hunt JP, Kandeel F, Kloos RT, Kopp P, Lamonica DM, Loree TR, Lydiatt WM, McCaffrey J, Moley JF, Olson JA, Parks 1, Ridge JA, Shah JP, Sherman SI, Sturgeon C, Waguespack SG, Wang TN, Wirth J: National Comprehensive Cancer Network (NCCN) guidelines on thyroid carcinoma. 2012. http://www.nccn.org/index.asp.

3 Physicians RCo: Guidelines for the management of thyroid cancer. 2007. http://www. british-thyroid-association.org.
4 Gharib H, Papini E, Paschke R, Duick DS, Valcavi R, Hegedus L, et al: American Association of Clinical Endocrinologists, Associazione Medici Endocrinologi, and European Thyroid Association medical guidelines for clinical practice for the diagnosis and management of thyroid nodules: executive summary of recommendations. J Endocrinol Invest 2010;33:51-56.

5 Schlumberger M BL, Dralle H, Jarzab B, Pacini F, Smit JW, European Task Force: 2012 European Thyroid Association guidelines for metastatic medullary thyroid cancer. Eur Thyroid J 2012;1:5-14.

6 Hazard JB, Hawk WA, Crile G Jr: Medullary (solid) carcinoma of the thyroid: a clinicopathologic entity. J Clin Endocrinol Metab 1959;19:152-161.
Melvin KE, Tashjian AH Jr: The syndrome of excessive thyrocalcitonin produced by medullary carcinoma of the thyroid. Proc Natl Acad Sci USA 1968;59:1216-1222.

$>8$ Bergholm U, Adami HO, Telenius-Berg M, Johansson $\mathrm{H}$, Wilander E: Incidence of sporadic and familial medullary thyroid carcinoma in Sweden 1959 through 1981: a nationwide study in 126 patients - Swedish MCT Study Group. Acta Oncol 1990;29:9-15.

-9 Bhattacharyya N: A population-based analysis of survival factors in differentiated and medullary thyroid carcinoma. Otolaryngol Head Neck Surg 2003;128:115-123.

10 Christensen SB, Ljungberg O, Tibblin S: A clinical epidemiologic study of thyroid carcinoma in Malmo, Sweden. Curr Probl Cancer 1984;8:1-49. 
-11 Gharib H, McConahey WM, Tiegs RD, Bergstralh EJ, Goellner JR, Grant CS, et al: Medullary thyroid carcinoma: clinicopathologic features and long-term follow-up of $65 \mathrm{pa}$ tients treated during 1946 through 1970. Mayo Clin Proc 1992;67:934-940.

$\checkmark 12$ Kebebew E, Ituarte PH, Siperstein AE, Duh QY, Clark OH: Medullary thyroid carcinoma: clinical characteristics, treatment, prognostic factors, and a comparison of staging systems. Cancer 2000;88:1139-1148.

13 Machens A, Niccoli-Sire P, Hoegel J, FrankRaue K, van Vroonhoven TJ, Roeher HD, et al: Early malignant progression of hereditary medullary thyroid cancer. N Engl J Med 2003;349:1517-1525.

14 Niccoli-Sire P, Murat A, Baudin E, Henry JF, Proye C, Bigorgne JC, et al: Early or prophylactic thyroidectomy in MEN 2/FMTC gene carriers: results in 71 thyroidectomized patients - the French Calcitonin Tumours Study Group (GETC). Eur J Endocrinol 1999; 141:468-474.

-15 Sanso GE, Domene HM, Garcia R, Pusiol E, de $M$, Roque M, et al: Very early detection of RET proto-oncogene mutation is crucial for preventive thyroidectomy in multiple endocrine neoplasia type 2 children: presence of C-cell malignant disease in asymptomatic carriers. Cancer 2002;94:323-330.

-16 Moline J, Eng C: Multiple endocrine neoplasia type 2: an overview. Genet Med 2011;13: 755-764.

17 Gertner ME, Kebebew E: Multiple endocrine neoplasia type 2. Curr Treat Options Oncol 2004;5:315-325.

-18 Keiser HR, Beaven MA, Doppman J, Wells S Jr, Buja LM: Sipple's syndrome: medullary thyroid carcinoma, pheochromocytoma, and parathyroid disease - studies in a large family. NIH conference. Ann Intern Med 1973;78:561-579.

19 Cunliffe WJ, Hudgson P, Fulthorpe JJ, Black MM, Hall R, Johnston ID, et al: A calcitoninsecreting medullary thyroid carcinoma associated with mucosal neuromas, marfanoid features, myopathy and pigmentation. Am J Med 1970;48:120-126.

-20 Farndon JR, Leight GS, Dilley WG, Baylin SB, Smallridge RC, Harrison TS, et al: Familial medullary thyroid carcinoma without associated endocrinopathies: a distinct clinical entity. Br J Surg 1986;73:278-281.

-21 Block MA, Jackson CE, Greenawald KA, Yott JB, Tashjian AH Jr: Clinical characteristics distinguishing hereditary from sporadic medullary thyroid carcinoma: treatment implications. Arch Surg 1980;115:142-148.

-22 Wolfe HJ, Delellis RA: Familial medullary thyroid carcinoma and $\mathrm{C}$ cell hyperplasia. Clin Endocrinol Metab 1981;10:351-365.
23 Romei C, Cosci B, Renzini G, Bottici V, Molinaro E, Agate L, et al: RET genetic screening of sporadic medullary thyroid cancer (MTC) allows the preclinical diagnosis of unsuspected gene carriers and the identification of a relevant percentage of hidden familial MTC (FMTC). Clin Endocrinol 2011;74:241-247.

24 Carney JA, Roth SI, Heath H, 3rd, Sizemore GW, Hayles AB: The parathyroid glands in multiple endocrine neoplasia type $2 \mathrm{~b}$. Am J Pathol 1980;99:387-398.

25 Williams ED, Pollock DJ: Multiple mucosal neuromata with endocrine tumours: a syndrome allied to von Recklinghausen's disease. J Pathol Bacteriol 1966;91:71-80.

-26 Gagel RF, Levy ML, Donovan DT, Alford BR, Wheeler T, Tschen JA: Multiple endocrine neoplasia type $2 \mathrm{a}$ associated with cutaneous lichen amyloidosis. Ann Intern Med 1989; 111:802-806.

27 Ceccherini I, Romei C, Barone V, Pacini F, Martino E, Loviselli A, et al: Identification of the Cys634->Tyr mutation of the RET proto-oncogene in a pedigree with multiple endocrine neoplasia type $2 \mathrm{~A}$ and localized cutaneous lichen amyloidosis. J Endocrinol Invest 1994;17:201-204.

28 Elisei R: Routine serum calcitonin measurement in the evaluation of thyroid nodules. Best Pract Res Clin Endocrinol Metab 2008; 22:941-953.

29 Pacini F, Fontanelli M, Fugazzola L, Elisei R, Romei C, Di Coscio G, et al: Routine measurement of serum calcitonin in nodular thyroid diseases allows the preoperative diagnosis of unsuspected sporadic medullary thyroid carcinoma. J Clin Endocrinol Metab 1994;78:826-829.

30 Doyle P, Duren C, Nerlich K, Verburg FA, Grelle I, Jahn H, et al: Potency and tolerance of calcitonin stimulation with high-dose calcium versus pentagastrin in normal adults. J Clin Endocrinol Metab 2009;94:2970-2974.

31 Colombo C, Verga U, Mian C, Ferrero S, Perrino $\mathrm{M}$, Vicentini L, et al: Comparison of calcium and pentagastrin tests for the diagnosis and follow-up of medullary thyroid cancer. J Clin Endocrinol Metab 2012;97:905-913.

32 Elisei R, Romei C, Renzini G, Bottici V, Cosci B, Molinaro E, et al: The timing of total thyroidectomy in RET gene mutation carriers could be personalized and safely planned on the basis of serum calcitonin: 18 years experience at one single center. J Clin Endocrinol Metab 2012;97:426-435.

33 Frank-Raue K, Buhr H, Dralle H, Klar E, Senninger $\mathrm{N}$, Weber $\mathrm{T}$, et al: Long-term outcome in 46 gene carriers of hereditary medullary thyroid carcinoma after prophylactic thyroidectomy: impact of individual RET genotype. Eur J Endocrinol 2006;155:229-236.

- 34 Scheuba C, Kaserer K, Bieglmayer C, Asari $\mathrm{R}$, Riss P, Drosten R, et al: Medullary thyroid microcarcinoma recommendations for treatment - a single-center experience. Surgery 2007;142:1003-1010, discussion 1010 . e1-e3.
35 Rohmer V, Vidal-Trecan G, Bourdelot A, Niccoli P, Murat A, Wemeau JL, et al: Prognostic factors of disease-free survival after thyroidectomy in 170 young patients with a RET germline mutation: a multicenter study of the Groupe Francais d'Etude des Tumeurs Endocrines. J Clin Endocrinol Metab 2011; 96:E509-E518.

36 Guerrero MA, Clark OH: Controversies in the management of papillary thyroid cancer revisited. ISRN Oncol 2011;2011:303128.

37 Bieglmayer C, Scheuba C, Niederle B, Flores J, Vierhapper H: Screening for medullary thyroid carcinoma: experience with different immunoassays for human calcitonin. Wien Klin Wochenschr 2002;114:267-273.

38 Tommasi M, Brocchi A, Cappellini A, Raspanti S, Mannelli M: False serum calcitonin high levels using a non-competitive two-site IRMA. J Endocrinol Invest 2001;24:356360.

39 Basuyau JP, Mallet E, Leroy M, Brunelle P: Reference intervals for serum calcitonin in men, women, and children. Clin Chem 2004; 50:1828-1830.

40 Verga U, Morpurgo PS, Vaghi I, Radetti G, Beck-Peccoz P: Normal range of calcitonin in children measured by a chemiluminescent two-site immunometric assay. Horm Res 2006;66:17-20.

-41 Santoro M, Melillo RM, Carlomagno F, Vecchio G, Fusco A: Minireview: RET - normal and abnormal functions. Endocrinology 2004;145:5448-5451.

-42 Santoro M, Rosati R, Grieco M, Berlingieri MT, D'Amato GL, de Franciscis V, et al: The ret proto-oncogene is consistently expressed in human pheochromocytomas and thyroid medullary carcinomas. Oncogene 1990;5: 1595-1598.

43 Arighi E, Borrello MG, Sariola H: RET tyrosine kinase signaling in development and cancer. Cytokine Growth Factor Rev 2005; 16:441-467.

44 Mathew CG, Chin KS, Easton DF, Thorpe K, Carter C, Liou GI, et al: A linked genetic marker for multiple endocrine neoplasia type 2A on chromosome 10. Nature 1987; 328:527-528.

45 Simpson NE, Kidd KK, Goodfellow PJ, McDermid H, Myers S, Kidd JR, et al: Assignment of multiple endocrine neoplasia type $2 \mathrm{~A}$ to chromosome 10 by linkage. Nature 1987;328:528-530.

46 Ishizaka Y, Itoh F, Tahira T, Ikeda I, Sugimura T, Tucker J, et al: Human ret proto-oncogene mapped to chromosome 10q11.2. Oncogene 1989;4:1519-1521.

47 Mulligan LM, Kwok JB, Healey CS, Elsdon MJ, Eng C, Gardner E, et al: Germ-line mutations of the RET proto-oncogene in multiple endocrine neoplasia type 2A. Nature 1993; 363:458-460. 
-48 Donis-Keller H, Dou S, Chi D, Carlson KM, Toshima K, Lairmore TC, et al: Mutations in the RET proto-oncogene are associated with MEN 2A and FMTC. Hum Mol Genet 1993; 2:851-856.

-49 Eng C, Smith DP, Mulligan LM, Nagai MA, Healey CS, Ponder MA, et al: Point mutation within the tyrosine kinase domain of the RET proto-oncogene in multiple endocrine neoplasia type $2 \mathrm{~B}$ and related sporadic tumours. Hum Mol Genet 1994;3:237-241.

-50 Elisei R, Cosci B, Romei C, Agate L, Piampiani P, Miccoli $\mathrm{P}$, et al: Identification of a novel point mutation in the RET gene (Ala883Thr), which is associated with medullary thyroid carcinoma phenotype only in homozygous condition. J Clin Endocrinol Metab 2004;89:5823-5827.

- 51 Cosci B, Vivaldi A, Romei C, Gemignani F, Landi S, Ciampi R, et al: In silico and in vitro analysis of rare germline allelic variants of RET oncogene associated with medullary thyroid cancer. Endocr Relat Cancer 2011;18: 603-6012.

52 Machens A, Spitschak A, Lorenz K, Putzer BM, Dralle H: Germline RET sequence variation I852M and occult medullary thyroid cancer: harmless polymorphism or causative mutation? Clin Endocrinol 2011;75:801-805.

53 Bihan H, Baudin E, Meas T, Leboulleux S, Al Ghuzlan A, Hannoteaux V, et al: Role of prophylactic thyroidectomy in RET 790 familial medullary thyroid carcinoma. Head Neck 2012;34:493-498.

-54 Elisei R, Cosci B, Romei C, Bottici V, Sculli M, Lari R, et al: RET exon 11 (G691S) polymorphism is significantly more frequent in sporadic medullary thyroid carcinoma than in the general population. J Clin Endocrinol Metab 2004;89:3579-3584.

-55 Gimm O, Neuberg DS, Marsh DJ, Dahia PL, Hoang-Vu C, Raue F, et al: Over-representation of a germline RET sequence variant in patients with sporadic medullary thyroid carcinoma and somatic RET codon 918 mutation. Oncogene 1999;18:1369-1373.

56 Ruiz A, Antinolo G, Fernandez RM, Eng C, Marcos I, Borrego S: Germline sequence variant S836S in the RET proto-oncogene is associated with low level predisposition to sporadic medullary thyroid carcinoma in the Spanish population. Clin Endocrinol 2001;55:399-402.

57 Machens A, Frank-Raue K, Lorenz K, Rondot S, Raue F, Dralle H: Clinical relevance of RET variants G691S, L769L, S836S and S904S to sporadic medullary thyroid cancer. Clin Endocrinol 2012;76:691-697.

58 Figlioli G, Landi S, Romei C, Elisei R, Gemignani $\mathrm{F}$ : Medullary thyroid carcinoma (MTC) and RET proto-oncogene: mutation spectrum in the familial cases and a metaanalysis of studies on the sporadic form. Mutat Res 2012, DOI: 10.1016/j.mrrev. 2012. 09.002 .
Metzker ML: Emerging technologies in DNA sequencing. Genome Res 2005; 15 : 1767-1776.

60 Metzker ML: Sequencing technologies - the next generation. Nat Rev Genet 2010;11:3146.

61 Schuffenecker I, Ginet N, Goldgar D, Eng C, Chambe B, Boneu A, et al: Prevalence and parental origin of de novo RET mutations in multiple endocrine neoplasia type $2 \mathrm{~A}$ and $\mathrm{fa}$ milial medullary thyroid carcinoma - Le Groupe d'Etude des Tumeurs a Calcitonine. Am J Hum Genet 1997;60:233-237.

62 Eng C, Clayton D, Schuffenecker I, Lenoir G, Cote G, Gagel RF, et al: The relationship between specific RET proto-oncogene mutations and disease phenotype in multiple endocrine neoplasia type 2: international RET mutation consortium analysis. JAMA 1996; 276:1575-1579.

63 Niccoli-Sire P, Murat A, Rohmer V, Franc S, Chabrier G, Baldet L, et al: Familial medullary thyroid carcinoma with noncysteine ret mutations: phenotype-genotype relationship in a large series of patients. J Clin Endocrinol Metab 2001;86:3746-3753.

64 Machens A, Gimm O, Hinze R, Hoppner W, Boehm BO, Dralle H: Genotype-phenotype correlations in hereditary medullary thyroid carcinoma: oncological features and biochemical properties. J Clin Endocrinol Metab 2001:86:1104-1109.

65 Gimm O, Marsh DJ, Andrew SD, Frilling A, Dahia PL, Mulligan LM, et al: Germline dinucleotide mutation in codon 883 of the RET proto-oncogene in multiple endocrine neoplasia type 2B without codon 918 mutation. J Clin Endocrinol Mmetab 1997;82:39023904.

66 Menko FH, van der Luijt RB, de Valk IA, Toorians AW, Sepers JM, van Diest PJ, et al: Atypical MEN type 2B associated with two germline RET mutations on the same allele not involving codon 918. J Clin Endocrinol Metab 2002;87:393-397.

-67 Tessitore A, Sinisi AA, Pasquali D, Cardone $\mathrm{M}$, Vitale D, Bellastella A, et al: A novel case of multiple endocrine neoplasia type $2 \mathrm{~A}$ associated with two de novo mutations of the RET protooncogene. J Clin Endocrinol Metabolism 1999;84:3522-3527.

68 Conzo G, Circelli L, Pasquali D, Sinisi A, Sabatino L, Accardo G, et al: Lessons to be learned from the clinical management of a MEN 2A patient bearing a novel 634/640/700 triple mutation of the RET proto-oncogene. Clin Endocrinol (Oxf) 2012;77:934-936.

-69 Eng C, Mulligan LM, Smith DP, Healey CS, Frilling A, Raue F, et al: Low frequency of germline mutations in the RET proto-oncogene in patients with apparently sporadic medullary thyroid carcinoma. Clin Endocrinol 1995;43:123-127.
70 Romei C, Mariotti S, Fugazzola L, Taccaliti A, Pacini F, Opocher G, et al: Multiple endocrine neoplasia type 2 syndromes (MEN 2): results from the ItaMEN network analysis on the prevalence of different genotypes and phenotypes. Eur J Endocrinol 2010;163:301308

71 Elisei R, Romei C, Cosci B, Agate L, Bottici $\mathrm{V}$, Molinaro E, et al: RET genetic screening in patients with medullary thyroid cancer and their relatives: experience with 807 individuals at one center. J Clin Endocrinol Metab 2007;92:4725-4729.

72 Sarika HL, Papathoma A, Garofalaki M, Vasileiou V, Vlassopoulou B, Anastasiou E, et al: High prevalence of exon 8 g533c mutation in apparently sporadic medullary thyroid carcinoma in Greece. Clin Endocrinol (Oxf) 2012;77:857-862.

$\checkmark 73$ Machens A, Dralle H: Multiple endocrine neoplasia type 2 and the RET protooncogene: from bedside to bench to bedside. Mol Cell Endocrinol 2006;247:34-40.

74 Fishbein L, Nathanson KL: Pheochromocytoma and paraganglioma: understanding the complexities of the genetic background. Cancer Genet 2012;205:1-11.

75 Binkley N, Ramamurthy R, Krueger D: Low vitamin D status: definition, prevalence, consequences, and correction. Rheum Dis Clin North Am 2012;38:45-59.

-76 Cetani F, Pardi E, Borsari S, Marcocci C: Molecular pathogenesis of primary hyperparathyroidism. J Endocrinol Invest 2011;34:3539.

77 Rothberg AE, Raymond VM, Gruber SB, Sisson J: Familial medullary thyroid carcinoma associated with cutaneous lichen amyloidosis. Thyroid 2009;19:651-655.

78 Amiel J, Sproat-Emison E, Garcia-Barcelo M, Lantieri F, Burzynski G, Borrego S, et al: Hirschsprung disease, associated syndromes and genetics: a review. J Med Genet 2008;45: $1-14$

79 Lantieri F, Griseri P, Ceccherini I: Molecular mechanisms of RET-induced Hirschsprung pathogenesis. Ann Med 2006;38:11-19.

80 Moore SW, Zaahl M: Familial associations in medullary thyroid carcinoma with Hirschsprung disease: the role of the RETC620 'Janus' genetic variation. J Pediatr Surg 2010;45:393-396.

-81 Arighi E, Popsueva A, Degl'Innocenti D, Borrello MG, Carniti C, Perala NM, et al: Biological effects of the dual phenotypic Janus mutation of ret cosegregating with both multiple endocrine neoplasia type 2 and Hirschsprung's disease. Mol Endocrinol 2004;18:1004-1017.

82 Frank-Raue K, Rybicki LA, Erlic Z, Schweizer H, Winter A, Milos I, et al: Risk profiles and penetrance estimations in multiple endocrine neoplasia type $2 \mathrm{~A}$ caused by germline RET mutations located in exon 10. Hum Mutat 2011;32:51-58. 
83 Niccoli P, Wion-Barbot N, Caron P, Henry JF, de Micco C, Saint Andre JP, et al: Interest of routine measurement of serum calcitonin: study in a large series of thyroidectomized patients - the French Medullary Study Group. J Clin Endocrinol Metab 1997;82: 338-341.

84 Brandi ML, Gagel RF, Angeli A, Bilezikian JP, Beck-Peccoz P, Bordi C, et al: Guidelines for diagnosis and therapy of MEN type 1 and type 2. J Clin Endocrinol Metab 2001;86: 5658-5671.

85 Graze K, Spiler IJ, Tashjian AH Jr, Melvin KE, Cervi-Skinner S, Gagel RF, et al: Natural history of familial medullary thyroid carcinoma: effect of a program for early diagnosis. N Engl J Med 1978;299:980-985.

\$86 Fleming JB, Lee JE, Bouvet M, Schultz PN, Sherman SI, Sellin RV, et al: Surgical strategy for the treatment of medullary thyroid carcinoma. Ann Surg 1999;230:697-707.

87 Hallwirth U, Flores J, Kaserer K, Niederle B: Differentiated thyroid cancer in children and adolescents: the importance of adequate surgery and review of literature. Eur J Pediatr Surg 1999;9:359-363.

88 Skinner MA, Moley JA, Dilley WG, Owzar K, Debenedetti MK, Wells SA Jr: Prophylactic thyroidectomy in multiple endocrine neoplasia type 2A. N Engl J Med 2005;353:11051113.

89 Sciume C, Geraci G, Pisello F, Facella T, Li Volsi F, Licata A, et al: Complications in thyroid surgery: symptomatic post-operative hypoparathyroidism incidence, surgical technique, and treatment (in Italian). Ann Ital Chir 2006;77:115-122.

90 Thomusch O, Machens A, Sekulla C, Ukkat J, Brauckhoff M, Dralle H: The impact of surgical technique on postoperative hypoparathyroidism in bilateral thyroid surgery: a multivariate analysis of 5,846 consecutive patients. Surgery 2003;133:180-185.

91 Parker M, Lucassen A: Concern for families and individuals in clinical genetics. J Med Ethics 2003;29:70-73.
92 Godard B, Hurlimann T, Letendre M, Egalite $\mathrm{N}$ : Guidelines for disclosing genetic information to family members: from development to use. Fam Cancer 2006;5:103-116.

93 Lacroix M, Nycum G, Godard B, Knoppers BM: Should physicians warn patients' relatives of genetic risks? CMAJ 2008;178:593595.

94 Clarke A, Richards M, Kerzin-Storrar L, Halliday J, Young MA, Simpson SA, et al: Genetic professionals' reports of nondisclosure of genetic risk information within families. Eur J Hum Genet 2005;13:556-562.

95 Marsh DJ, Learoyd DL, Andrew SD, Krishnan L, Pojer R, Richardson AL, et al: Somatic mutations in the RET proto-oncogene in sporadic medullary thyroid carcinoma. Clin Endocrinol (Oxf) 1996;44:249-257.

96 Romei C, Elisei R, Pinchera A, Ceccherini I, Molinaro E, Mancusi F, et al: Somatic mutations of the ret protooncogene in sporadic medullary thyroid carcinoma are not restricted to exon 16 and are associated with tumor recurrence. J Clin Endocrinol Metab 1996;81:1619-1622.

-97 Lindsey SC, Kunii IS, Germano-Neto F, Sittoni MY, Camacho CP, Valente FO, et al: Extended RET gene analysis in patients with apparently sporadic medullary thyroid cancer: clinical benefits and cost. Horm Cancer 2012;3:181-186.

98 Zedenius J, Larsson C, Bergholm U, Bovee J, Svensson A, Hallengren B, et al: Mutations of codon 918 in the RET proto-oncogene correlate to poor prognosis in sporadic medullary thyroid carcinomas. J Clin Endocrinol Metab 1995;80:3088-3090.

99 Elisei R, Cosci B, Romei C, Bottici V, Renzini G, Molinaro E, et al: Prognostic significance of somatic RET oncogene mutations in sporadic medullary thyroid cancer: a 10 -year follow-up study. J Clin Endocrinol Metab 2008;93:682-687.
00 Moura MM, Cavaco BM, Pinto AE, Domingues R, Santos JR, Cid MO, et al: Correlation of RET somatic mutations with clinicopathological features in sporadic medullary thyroid carcinomas. Br J Cancer 2009;100:1777-1783.

101 Schilling T, Burck J, Sinn HP, Clemens A, Otto HF, Hoppner W, et al: Prognostic value of codon 918 (ATG->ACG) RET protooncogene mutations in sporadic medullary thyroid carcinoma. Int J Cancer 2001;95: 62-66.

102 Mian C, Pennelli G, Barollo S, Cavedon E, Nacamulli D, Vianello F, et al: Combined RET and Ki-67 assessment in sporadic medullary thyroid carcinoma: a useful tool for patient risk stratification. Eur J Endocrinol 2011;164:971-976.

103 Schlumberger M, Carlomagno F, Baudin E, Bidart JM, Santoro M: New therapeutic approaches to treat medullary thyroid carcinoma. Nat Clin Pract Endocrinol Metab 2008;4:22-32.

104 Wells SA Jr, Robinson BG, Gagel RF, Dralle $\mathrm{H}$, Fagin JA, Santoro M, et al: Vandetanib in patients with locally advanced or metastatic medullary thyroid cancer: a randomized, double-blind phase III trial. J Clin Oncol 2012;30:134-141.

105 Boichard A, Croux L, Al Ghuzlan A, Broutin S, Dupuy C, Leboulleux S, et al: Somatic RAS mutations occur in a large proportion of sporadic RET-negative medullary thyroid carcinomas and extend to a previously unidentified exon. J Clin Endocrinol Metab 2012;97:E2031-E2035.

106 Ciampi R, Mian C, Fugazzola L, Cosci B, Romei C, Barollo S, et al: Evidence of a low prevalence of Ras mutations in a large medullary thyroid cancer series. Thyroid 2012, E-pub ahead of print.

107 Moura MM, Cavaco BM, Pinto AE, Leite V: High prevalence of RAS mutations in RETnegative sporadic medullary thyroid carcinomas. J Clin Endocrinol Metab 2011; 96:E863-E868. 